\title{
Study on the Microscopic Path of the Transformation from Traditional Stereotypical Education to Professionalism of the College Education
}

\author{
Yanjie Zhan \\ College of Business Administration, Tonghua Normal University, Tonghua, China \\ 82509380@qq.com
}

\begin{abstract}
Keywords: College education; Stereotypical education; Professionalism; Microscopic path of the transformation
\end{abstract}

\begin{abstract}
The college education professionalization reform is an important support for the "composite" talents. The discourses of the current traditional stereotypical education are not exact enough. And it is macroscopic of the direction of the professionalization reform. It is to transform to professional comprehensive quality cultivation with combination of the examination-oriented education, to explore the transformation from solid "industrial model" to dynamic career mode, to carry out the microscopic path of the transformation from the traditional stereotypical education to professionalism of the college education in order to provide great impetus for the professional development of the college education.
\end{abstract}

\section{Introduction}

The further exploration of the path of the college education professionalization reform is a prerequisite for the talents cultivation of "compound type", "research type", "innovative type" with the time's obligation and requirement to promote the comprehensive development of the society. Relevant scholars put forward the specific point of view on traditional stereotypical education. In the Zhang Xiaoyan's opinion, due to the factors of the utilitarian tendency of college education, the influence of the traditional exam-oriented education mode and the insufficiency of the faculty. The only way to achieve the aim of cultivating qualified college students is innovation.. Liu Jikun and Kou Yueling come up with the ideas that there are lots of maladaptation in the process of the connection of the traditional personnel training mode with international. And it is an important topic of the high education reform to cultivate a large number of qualified applied talents for the socialist modernization taking examples of the advanced methods of talent training from developed countries[1]. The views of the traditional stereotypical education reform are generally with macroscopic characteristics, building up a professional education mode with quality-oriented education as the core. The research perspectives cannot highlight the specific transformation construction plan or the analysis or exploration of relevant stressed objects. Through the analysis on the stressed objects of the college education professionalism transformation, it is to state the transform to professional comprehensive quality cultivation from the examination-oriented education, which builds up the transformation path from solid "industrial model" to dynamic career mode in order to provide great impetus for the professional development of the college education.

\section{Analysis on the Stressed Objects of the Transformation of the College Education Professionalism}

The stressed objects of the college education professionalism transformation stresses on cultivation and guidance of professional ability and quality and the improvement and identification of professional skills[2]. The cultivation of professional ability includes a wide scope of factors with essential difference from college traditional exam-oriented education and stereotypical education. Ministry of education in 2014 puts forward below working points: "study and make the instructions of the development of the transformation of undergraduate colleges, launch and implement the trial place of the national and provincial reform, instruct a number of undergraduate colleges to transform 
to high colleges of application types, which means higher education in our country will come to a new period with layout structure adjusting by the government's promotion[3]. The key points of the exam-oriented education and stereotypical education are reflected by two aspects: First, the view of high grade is strong, by which the students' studying effects are generally confirmed and which is considered as the intuitive condition to identify the students' abilities and quality development. Second, it emphasizes on the wide and united directions of talent cultivation, partially requires a popular training for students and neglects the students' personality development with obvious deficiency on the innovation motivity which makes the students not able to fit their careers in working. Education professionalism transformation is based on the comprehensive evaluation and appraisal of students' professional quality, ability and skill, identifying the innovation of their operator skills, at the same time inspecting the psychology degree of students' vocational moral cognition, which reflects the cultivating effect of the higher college students' adaptive capacity and communication competence in order to provide objective information to realize the students' professional development goals. This is the striking contrast between the stressed objects of the college education professionalism transformation and the cultivating view of traditional exam-oriented education and stereotypical education. It is to discuss the breakthrough direction of reform and the implementation through deep study of transformation from the traditional stereotypical education and traditional exam-oriented education to professionalism education.

\section{Transform Subject Exam-oriented Education to Professional Comprehensive Quality Cultivation}

Tranditional "High Grade" Education Thoughts Updated to Vocational EducationIdea as "High-energy". The key of the transform to professional comprehensive quality cultivation from the current subject examination - oriented education in higher colleges transfers the thought construct from traditional exam-oriented education mode with ideas of high grade education thought to vocational education idea as high-energy and to transfer the paper examination to competence test to cultivate the students' thoughts to seek truth. Based on the subjective practice condition transform of exam-oriented education it is to establish evaluation standard and path for professional quality in order to provide great impetus for the comprehensive development of students' professional quality.

Traditional exam-oriented education mode focuses too much on students' achievement, ignores the students' ability of practical development and considers scores to reflect the students' ability. The characteristics of the two matches each other. But in the exam-oriented education mode, students master the theoretical knowledge better with cultivation on ability of operating and innovation relatively lagged, which causes a wide appearance of "high score low-energy" among the students and the score becomes the "obstacle" for students' career development. The development of modern social economy determines that the modern higher education must be geared to the needs of economic construction and social development of the school taking initiative to adapt to and serve for the needs of the economic construction and development of ecological civilization[4]. "Occupational orientation" is the value pursuit of modern colleges different from traditional colleges, and professionalism is the prominent feature of modern higher education different from traditional higher education. Aiming at the cultivation of vocational ability, the high college education shall base on expand and guiding of college education form and career goals to make the practice education model and professional communication education mode as the important breakthrough direction, to establish views of students' professional operating skills, professional innovation ability and professional communication ability in order to gradually guide students to make a reasonable plan for their own career goal in order to maintain unity between theoretical knowledge and practical application, the theoretical knowledge and professional skills training for the students.

Take "Try" as the Main Body to Transfer to Direction of "Seek for Truth" of Professional Ability. The transformation from college exam-oriented education to the professional comprehensive quality cultivation shall be transferred based on knowledge and understanding of the test process to 
appraisal process of cultivating the ability of students, which establishes the spirit of seeking truth during cultivation of students ability to promote all-round development of students' professional quality[5]. With the deep comprehensive reform of the education field, the development of the local colleges has proposed new strategies of transformation. But in the development of local colleges transformation, there are still divergence on some problems and certain deviation in the concepts of people. Exams of specialized courses, required courses and elective courses in college exam-oriented education are the main means of college students' comprehensive quality evaluation, which are the representative factor of traditional college exam-oriented education thought. Examination of professional courses is divided into theory course exam and practice course evaluation, which mainly investigates students' mastering of theoretical knowledge and proficiency of practical operation. Compulsory courses and elective course examination is mainly based on theory of investigation to estimate the specific effect of students knowledge and understanding thereof. The exam gives priority to paper testing. The evaluation of students' competence is not the main body, which causes the evaluation of students' practical and innovation ability, research and exploration ability not highlighted enough. Combining the aim of "test" in college exam-oriented education, it shall discuss the directions of the students' abilities of practical innovation, practical exploration, autonomous cooperation and communication methods to establish the evaluation method and evaluation standard of students' vocational ability. Through internal and external form of professional education practice, it shall evaluate students' thoughts of practical operating innovative, understanding, thinking and interpersonal communication to make a practical guidance scheme to provide the students' psychology of seeking truth with scientific evaluation method and guiding path and to make the transformation from traditional exam-oriented education thought to vocational education thought, with identify of professional ability to be the view of the college education professional development.

Adjust the Subjective Implement Conditions of Exam-oriented Education to the Direction of Professional Quality Education. The main part of adjustment of subjective implement conditions of exam-oriented education to the direction of professional quality education is to transfer the ability evaluation method from knowledge into practice to discriminate the detailed conditions of students' professional quality cultivation through practical implementation. Among the subjective conditions of the traditional college exam-oriented education, it is obviously partial to judge the students' ability and quality, knowledge and skills by the paper tests. With the accelerating process of the development of modern society, students' ability, skill and quality are embodied in social and professional posts, which requires the professional practice to be the implement path of evaluating the operating skill, professional quality and innovation ability. In the professional development of college education, the implementation conditions of students' professional quality evaluation shall use the practical evaluation as the main line. And the evaluation standard uses the feasibility of students' operating skills innovation, the professional moral cognition, the influence of the professional conducting as the evaluation index, to identify students' comprehensive quality cultivation condition and to summarize the future development direction and prospect of comprehensive professional quality. Combined with the subjective conditions of contemporary professional quality education in colleges, it is to provide the development of students' intangible ability, skill and quality with consistent appraisal standards and appraisal method, to supplement one-sided idea in the exam-oriented education mode, to realize the comprehensive evaluation of knowledge and skill, ability and quality in order to lead to the professionalism reform of college education and the path ahead. Traditional modular talent training is the main performance of the modular of college education training, combining the transformation of view of the modular training mode to make a further statement to promote static modular training mode into dynamic vocational training mode.

\section{The Transform Path from a "Solid Industrial Model" to a Dynamic Career Mode}

The "Flow" Mode Transferred into "Upgrade Processing" Mode. Traditional "flow" pattern is mainly embodied in the stylization of student's knowledge and skills which intensifies the students' 
scope of knowledge and master degree in different steps following procedures, with wide conducting objects of knowledge and skills and lacking of the cultivation of students' quality and ability of a large area[6]. . Transformation of colleges is the entry point of our country's comprehensively deepen education reform in the field of education which has important significance to adjust the structure of higher education, train applied talents and serve to local or industry development. With ability and quality as key factors in the contemporary social standard demanding for talents, students' grasping of knowledge and skills can't decide the prospects of their future development. Facing the demand for professional standards and requirements, the professional moral quality, professional innovative abilities and language communication and expression ability, independent innovation, research and development ability become the top priority things in the "upgrade process" mode transformation of college education. Use the universality of knowledge and skills cultivation, through diverse practical activities in campus and in society to cultivate a divergent thought of college students in the field of professional application. It shall emphasize the comprehensive optimization of cognitive perspective of social humanistic care and social ideology to enhance students' innovation and exploring ability of knowledge skills application, at the same time to optimize students' cultural consciousness, sense of direction of the social development dynamic, to enhance students' professional ethics quality and to boost the sublimation of college students' vocational quality to achieve the overall requirements of "upgrade process" mode struction.

Transfer the Traditional Modular Talents Cultivation into a Humanization Guide. As the intermediate link, the transformation of the traditional modular talents cultivation to a humanization guide bears the development direction of college students towards professionalization with functions of connecting between the preceding and the following. The plans of college traditional modular of the talent training mainly consist of three modules: The first one is the theoretical teaching module; The second one is the practice education module; The third one is the quality leading module. The separated conditions exist in the three modules, leading to a lack of internal correlation in the cultivation of students' professional knowledge, ability and quality which cannot be coordinated and unified as a organism[7]. Theory teaching module focuses too much on mastering, strengthening and infusing the knowledge, the conduction of understanding and application of knowledge are not enough. Practical education module unilaterally focuses on the deepening of operating skills neglecting the ability to integrate theory with practice. The penetration of quality education in the practice education is relatively obscure. The quality education module cannot be known as the core of the education mode structure with thought education as the main body, and the spread and guide of professional moral quality are not comprehensive enough. college students' professional development to orientate college students with professional person's attitude and ,constantly strengthen their professional attitude and confidence[8]. With the main situation of cultivation plan of traditional modular building, transformation path of direction of humanization guide shall expand combined with three aspects: first one, to establish corresponding theoretical knowledge conduction process; second one, to provide a selective way of practice education; third one, to build personalized guide way of professional quality. Targeted conduction process of theory is combined with the feature of students' knowledge to establish the consistent means of guidance with ideas of understanding, mastering and application of knowledge to strengthen the innovation of knowledge application in order to pave the way for implement of practice education. It is to diversify the education content and research direction of the practical education in order to provide the necessary impetus for students to practice innovation by providing a selective way of practice education. Creating personalized professional quality guide way is the general rule combined with students' comprehensive quality to make the humanities education, career planning, career goals as an important part of guiding the improvement of students' professional comprehensive accomplishment, so that the humanization guide way is to interlock the traditional talent training modules and to make the coordinated development of knowledge, skill and quality as the foundation so as to provide students with ideal guide ideas. 
From Centralized Production Mode to Targeted Professional Service Mode. "Concentrate production" mode which is transformed to the targeted professional service mode, as the final step of modular education to professional education, is the core of transformation from solid "industrial model" to dynamic career mode . "Concentrate production", as the name suggests, is an unified manufacturing process of large area and integration which is also a common characteristic of traditional education in colleges. Targeted professional service mode which focuses on a direction of professional and services makes a summary and analysis on the possible problems and doubts in students' working posts to provide with targeted services in order to ensure the students to be adapt to the social practice environment. In the process of transformation two aspects shall be implemented on : one is the interpretation of the demand standard for professional talents; the other is to probe into the matching degree of the students' professional ability and quality with the requirements of the professional posts[9]. The overall direction of requirement of the modern social professional talent is the deep comprehension of the professional consciousness and professional innovation ability. The practice education and humanistic education in college students acts as the new factor to improve practice ability and quality. The practice innovation ability in practice education directly affects the development of the development of students' innovative thoughts. It becomes a key point to pay attention to the specific direction of the personnel demands of the posts[10]. The goal of cultivation of the students' vocational ability and comprehensive quality is to meet job requirements, to strengthen the expanding of students' ideological cognitive perspective and improve college students' professional comprehensive quality, with the knowledge innovation, skill innovation, ability innovation as a benchmark, to provide students with service of ability and consciousness towards the new road of vocational development with functions to answer questions of students' vocational development.

\section{Conclusions}

Study and exploration on the path of the transformation from traditional stereotypical education to professionalism education shall take into first account of the deep reading of the stressed objects of the professionalism education reform to make a specific analysis based on the main characteristics of the existing exam-oriented education mode and to research on the direction of transformation to vocational comprehensive quality cultivation. An analysis shall be made aiming at the main characteristics contained in the traditional solid "industrial model" to discuss the concrete scheme of transformation of dynamic career mode, to expand the reform route of college education professionalism and at the same time, to establish direction of comprehensive development of the professional quality.

\section{References}

[1] G.X.Zhao and S.D.Li: Management of observation, Vol. 29(2009) No.33, p.131-132.(In Chinese)

[2] Z.S.Jiang: The Practice and Research on the Professional Construction of Secondary Vocational Schools -- Taking Wenling Vocational School as an Example (MS., Zhejiang University of Technology, China 2015), p.22.(In Chinese)

[3] L.P.Zhang: Imparting Knowledge and Educating People, Vol.12(2015) No.4, p.4-5.(In Chinese)

[4] B.C.Hu and C.S.Zhang: Computer Knowledge and Skills, Vol.35 (2016) No.2, p.22-27.(In Chinese)

[5] D.K.Wang: Vocational and Technical Education, Vol.35(2015) No.12, p.28-32.(In Chinese)

[6] D.M.Li: Research on the Training Mode of GCEF Talents in Hotel Management Specialty in Higher Vocational Colleges (MS., Huaqiao University, China 2015), p.9.(In Chinese) 
[7] S.L.Leng and W.Shi: Curriculum Education Research, Vol. 10 (2016) No.25 p.1.(In Chinese)

[8] H.Xangand C.L.Zhao: Heilongjiang Researches on Higher Education, Vol. 10 (2015) No.9, p.27-29.(In Chinese)

[9] Y. Ge: Investigation and Research on the Information-based Teaching Ability of Middle School Teachers (MS., Huaqiao Normal University, China 2013), p.32.(In Chinese)

[10] Information on http://news.k618.cn/edus/201607/t20160714_8121206.html(In Chinese) 